\title{
ASSESSING THE ADOPTION OF E-GOVERNMENT USING TAM MODEL: CASE OF EGYPT
}

\author{
Sara ELKheshin ${ }^{1}$ and Noha Saleeb ${ }^{2}$ \\ ${ }^{1}$ Arab Academy for Science, Technology and Maritime Transport, Alexandria, Egypt \\ ${ }^{2}$ Middlesex University, London, UK
}

\begin{abstract}
Electronic government (e-government) was known as an efficient method for government expertness and proficiency as a vital facilitator for citizen-oriented services. Since their initiation over a decade ago, Egovernment services are recognised as a vehicle for accessing online public services. Both governments and academic researchers understand the difficulty of low-level adoption of e-government services among citizens; a common problem between both developing and developed countries. This paper investigates determinants and factors necessary to enhance adoption of citizens for e-government services in developing countries, with particular focus on Egypt, by extending the Technology Acceptance Model (TAM) using a set of political, social, and design constructs that were developed from different sources of research literature.
\end{abstract}

\section{KEYWORDS}

E-government, Adoption, Technology acceptance model, Adoption models

\section{INTRODUCTION}

Information and Communication Technology (ICT) is currently thought of as a key factor in developing any society. With the majority of countries globally having incorporated new technologies with links to the Internet and the World Wide Web, currently many governments are attempting to employ these technologies to develop the method by which they provide services to citizens.

E-government is defined as the use of information and communication technologies (ICT), especially the Internet and world-wide-web, to improve the efficiency, cost and quality of the government information and services provided to its stakeholders: citizens, businesses, employees and other government agencies [1]. The acceptance and success of e-government is dependent upon citizen willingness to adopt this innovation. However, many governments around the world still face the problem of low-level citizen adoption of e-government services especially in the Arab countries [2].

Without understanding what motivates the public to use e-government services, governments will not be able to take strategic actions to increase the e-government up-take [3]. However, our understanding of citizen adoption of e-government services is currently lacking due to the following reasons: 
International Journal of Managing Information Technology (IJMIT) Vol.12, No.1, February 2020

Although technology adoption from the user perspective has been extensively studied in contexts such as e-commerce and Internet [4], relatively few studies have focused on citizen adoption of egovernment services [5].

There is a lack of empirical research that considers technological issues of e-government adoption, as well as behavioural issues [5].

Therefore, more empirical studies are required in the area of the adoption of e-government to help governments to improve their understanding of the issues that affect citizen adoption of egovernment services. In addition, a careful review of the e-government adoption research shows that a large portion of the published research was conducted in developed countries. Hence, little is written about the factors influencing e-government adoption in developing countries.

Egypt has been selected for investigation as a representative of a developing country, which has a running e-government program since 2001 offering many transactional services [6]. Despite the high number of services offered online, limited numbers of users are using the services. Therefore, a better understanding of the factors that influence citizen adoption of e-government services is critical in Egypt. This research can also have important implications for other Arab countries with similar circumstances.

This paper presents the development of a new model for factors affecting e-government services adoption by integrating the TAM model with a set of social, political and design variables derived from the different research literatures: government and internet trust, perceived public value of egovernment (which is the value that the public can acquire through the use of e-government services), and website design. This extended TAM model is to examine the impact of these factors upon citizen adoption of e-government services in developing countries with similar national cultures and values, by specifically applying the new model to assess Egyptian egovernment adoption as a representative.

\section{TeChNOLOGY ACCEPTANCE MODELS}

\subsection{Theory of Reasoned Action (TRA)}

TRA is a well-accepted and widely studied intention model that has been used successfully to explain behaviour across a wide variety of settings [8]. According to TRA, an individual's behaviour is best predicted by his/her behavioural intention, which in turn is determined by the person's attitudes and subjective norm. TRA scope excludes a wide range of behaviours that are for instance impulsive, spontaneous, the result of cravings, or simply mindless because their performance may not be completely voluntary or because the engagement into these behaviours is not out of conscious intention of the actor to do so. In this research study related to e-government, users need specific skills, experiences and base of the understating of Internet technologies to be able to have clear behavioural intention on the acceptance of E-government, hence this model was not found suitable as an adoption model for e-government.

\subsection{Theory of Planned Behaviour (TPB)}

The Theory of Planned Behaviour (TPB) is proposed as an extension of the Theory of Reasoned Action (TRA, which was related to voluntary behaviour), because of the limitations of TRA in dealing with behaviours over which people have incomplete desire control. The TPB introduced a third independent determinant of intention, perceived behaviour control (PBC) [13]. 
International Journal of Managing Information Technology (IJMIT) Vol.12, No.1, February 2020

This TPB model, like TRA, lacks the users need for specific skills, experiences and base of the understating of Internet technologies to be able to have clear behavioural intention on the acceptance of E-government, hence this model was not found suitable as an adoption model for egovernment.

\subsection{Unified Theory of Acceptance and Use of Technology}

Venkatesh et al. [7] introduced the Unified Theory of Acceptance and Use of Technology, by synthesising constructs from eight existing technology acceptance models: TRA, TAM, TPB, the Motivational Model (MM), the combined TAM and TPB (C-TAM-TPB), the Model of PC Utilization (MPCU), DOI and Social Cognitive Theory (SCT). The authors argue that UTAUT provides a useful tool for managers to assess the likelihood of technology acceptance in the organisational context.

However, computer anxiety, computer self-efficiency, and attitude towards the use of technology were theorised not to be direct determinants of intention. These constructs were not included in the final model, therefore, this was not found suitable as an adoption model for e-government because the Attitude construct was omitted from the model, the importance of which for egovernment adoption is highlighted subsequently.

\section{RESEARCH MODEL AND HYPOTHESES}

\subsection{Technology Acceptance Model}

There are different models developed by the IS researchers to understand and predict technology acceptance and usage. The Technology Acceptance Model (TAM) which was created by Davis [24]; was the suitable model to be used in this research. The TAM model is one of the various models that IT/IS researchers have used to predict and explain the underlying factors that motivate users to accept and adopt new information technology systems.

TAM was the model used for technology acceptance of e-government in this research due to the following reasons: Its important attribute of being a generic model that can be applied to any context using ICT. Also it has received extensive support through validation, applications and replications for its power to predict use of information systems [25].

It is considered to be a well-established, well-tested, powerful, robust and parsimonious model for predicting user acceptance of technology [26] and the fact that various research and empirical studies used TAM in the context of e-government mainly to model users' behaviour and intention to use certain e-government systems or applications.

The ability to add external constructs or variables to the model (through perceived ease of use and perceived usefulness constructs) e.g. trust in Internet, website design as examples. This would enable testing their effects on the adoption of the technology, in this research being e-government services.

The fact the TAM model contains the Attitude variable that was not included in other versions of TAM and in the UTAUT model and using e-government needs specific skills, experiences and base of the understating of Internet technologies to be able to have cleared behavioural intention on the acceptance of E-government, this point was ignored by TRA and TPB but not by TAM. 
International Journal of Managing Information Technology (IJMIT) Vol.12, No.1, February 2020

TAM hypothesises that the acceptance of a new IS can be predicted based on users' behaviour intention (BI), attitude towards use (ATT), and two other internal beliefs: perceived usefulness (PU) and perceived ease of use (PEOU). Davis [8] defined perceived usefulness as "the degree to which a person believes that using a particular system would provide all the required information", perceived ease of use as "The degree to which a person believes that using a particular system would be free of mental effort", attitude as "An individual's positive or negative feelings (evaluative affect) about performing the target behaviour", behaviour intention is defined as "the strength of one's intention to perform a specified behaviour (towards innovation), and actual system usage".

Based on the original TAM construct relationships (figure 1, below), the magnitude of the following existing hypotheses are measured in this study:

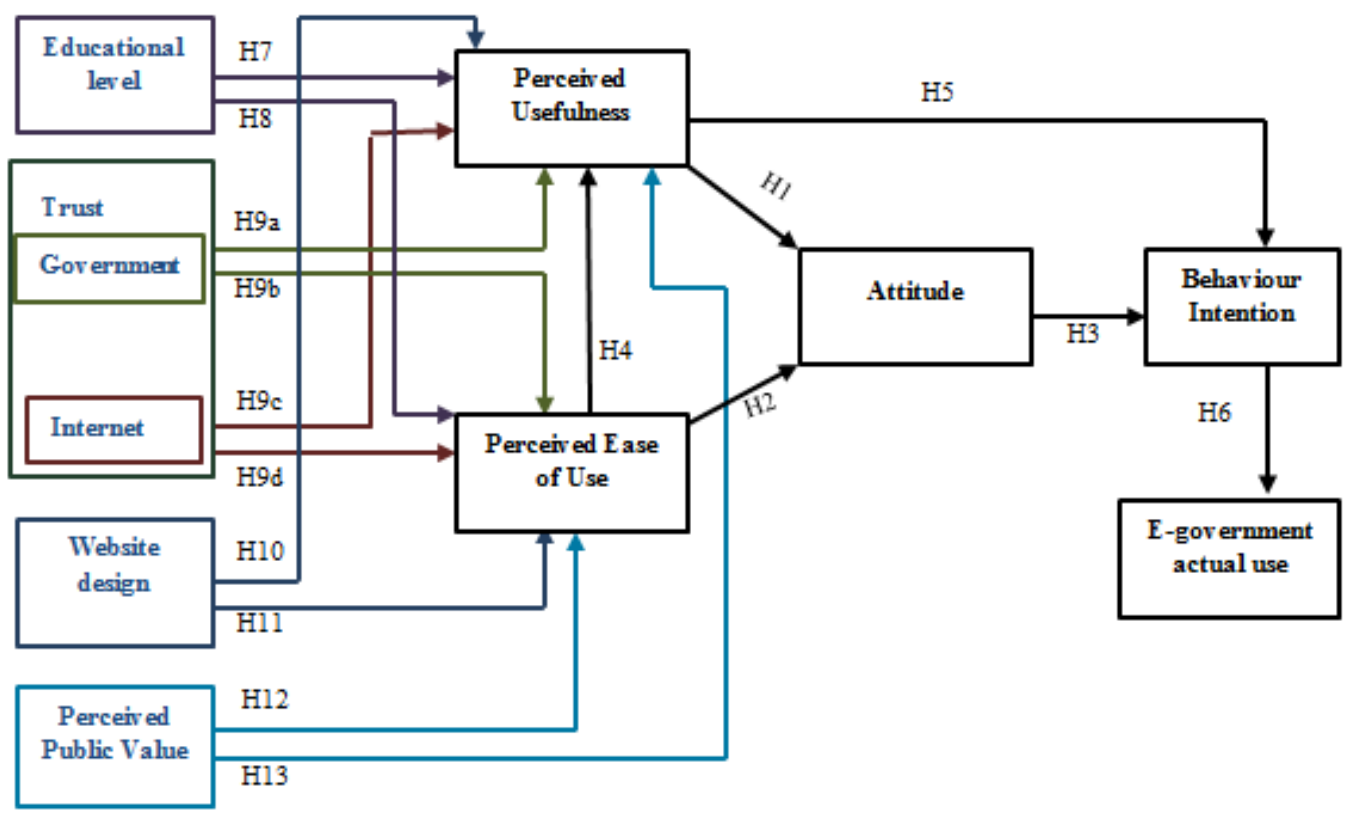

Figure1. Proposed Model (original five TAM constructs to the right)

\subsubsection{Perceived Usefulness}

High level of PU results in more positive attitude towards attitude (ATT) [2]. PU has been consistently found as a direct determinant of intention to use (BI), and also influences user's BI indirectly as a direct determinant of ATT [9].

H1: There is a direct and positive relationship between Perceived Usefulness (PU) and Attitude (ATT) towards using e-government services.

According to Davis [8], Customer's intention to adopt and make use of a certain technology depends not only on the attitude but also on how the customers believe that using e-government would provide all required information - i.e. usefulness. Fu et al. [9] found that behavioural intention was largely driven by perceived usefulness.

H5: There is a direct and positive relationship between Perceived Usefulness (PU) and Behaviour intention (BI) to use e-government services. 
International Journal of Managing Information Technology (IJMIT) Vol.12, No.1, February 2020

\subsubsection{Perceived Ease of Use}

Perceived ease of use is another determinant of attitude toward use in the TAM model. This internal belief ties to an individual's assessment of the mental effort involved in using a system [21]. Improvements of performance will be the result of the improvement of perceived ease of use.

$\mathrm{H} 2$ : There is a direct and positive relationship between Perceived Ease of Use (PEOU) and Attitude (ATT) towards using e-government services.

PEOU has been shown to influence behaviour through two causal ways: (1) an indirect effect on behaviour via ATT and (2) an indirect effect on behaviour via PU.

H4: There is a direct and positive relationship between Perceived Ease of Use (PEOU) and Perceived Usefulness (PU) of e-government services.

\subsubsection{Attitude}

Attitude is the variable that receives most attention. It is used widely for predicting customers"e likelihood to adopt a new technology" [27]. Practically Customers today have been exposed to a number of technology innovations. They are likely to have formed a positive or negative attitude about them irrespective of whether they have actually used the product in question. As an innovative system, e-Government is still in its early stage.

H3: There is a direct and positive relationship between Attitude (ATT) towards e-government and Behaviour Intention (BI) to using e-government services.

\subsubsection{Behaviour Intention}

The majority of technology adoption researchers have utilised behaviour intention to predict technology adoption. Also, Ajzen [10] suggests that behavioural intention is counted to have a direct influence on adoption. The measurement of behavioural intention includes the intention, and predicted use of e-government services.

H6: There is a direct and positive relationship between Behaviour intention (BI) to use egovernment services and E-government actual use.

\subsection{External Variables}

Perceived usefulness and perceived ease of use could be affected by external variables considered in the original TAM model. This study extends the original TAM by integrating the original TAM constructs with the new constructs: trust in government and in the internet, website design, perceived public value, and education level) to test how this new adjusted model of factors influences citizen adoption of e-government services. Hence the following new hypotheses are tested in this study:

\subsubsection{Education}

The decision to adopt a new technology is related to the amount of knowledge one has regarding how to use that technology appropriately, and complex technologies, such as the e-government, require more knowledge [19]. Early adopters of new technologies tend to have higher educational 
International Journal of Managing Information Technology (IJMIT) Vol.12, No.1, February 2020

levels, perhaps reflecting their ability to understand "how-to" knowledge more quickly than those with less education [19].

H7. Perceived Usefulness (PU) associated with the Internet is lower for individuals who are less educated.

H8. Perceived ease of use (PEOU) associated with the Internet is lower for individuals who are less educated.

\subsubsection{Trust}

Trust is emerging as a potentially important factor leading to IT acceptance; it plays a critical role in motivating consumers to purchase through the Internet. Trust issues are categorised as trust in the Internet in terms of security and privacy, and trust in government [11].

Trust in government can be defined as 'the public's assessment of government based on their perceptions of political authorities, agencies and institutions' integrity and capability to provide services according to the expectations held by the citizens" [11].

H9a: There is direct and positive relationship between Trust in the Government (TG) and Perceived Usefulness (PU).

H9b: There is direct and positive relationship between Trust in the Government (TG) and Perceived Ease of Use (PEOU).

Trust in the Internet is often identified as "institution-based trust [11], which is "the belief that needed structural conditions are present (e.g. in the internet) to enhance the probability of achieving a successful outcome in an endeavour like e-commerce" [12]. Prior research has extensively recognised trust in the Internet as a significant predictor of e-government services adoption.

H9c: There is direct and positive relationship between Trust in the Internet (TI) and Perceived Usefulness (PU).

H9d: There is direct and positive relationship between Trust in the Internet (TI) and Perceived Ease Of Use (PEOU).

\subsubsection{Website design}

As e-government websites have become the main channel for online interaction between the government and citizens, designing user-centred websites have become a concern of governments [16]. Bertot and Jaeger [17] argue that accessibility is one of the most important considerations in building useful user-centred e-government services. Studies demonstrate the importance of wellpresented content on government websites in ensuring citizens' satisfaction with the services provided [18]. Wang et al. state that without appropriate evaluation of web-based e-government services, some of the e-government benefits, such as fast access to government services and cost reduction, cannot be assured.

H10: There is direct and positive relationship between Website design (WD) and Perceived Usefulness (PU). 
International Journal of Managing Information Technology (IJMIT) Vol.12, No.1, February 2020

H11: There is direct and positive relationship between Website design (WD) and Perceived Ease of Use (PEOU).

\subsubsection{Perceived public value}

Perceived value is a subjective evaluation of the trade-off between all that is received, and all that is given up in the process of acquiring, or using a consumption related object (product, store, service) [14]. More attention has been paid recently to perceived value as a stable construct to predict buying behaviour. Indeed, customers' value perceptions have been found to influence customer behavioural intentions. It increases their willingness to buy a product or use a service, and decreases their intentions to trying to find an alternative [15].Empirically, less educated individuals report insufficient knowledge as one of the main reasons that they choose not to use the Internet [20].

H12: There is direct and positive relationship between Perceived public value (PPV) and the Perceived Ease of Use (PEOU) of e-government services.

H13: There is direct and positive relationship between Perceived public value (PPV) and the Perceived Usefulness (PU) of e-government services.

\section{SAMPLE AND SURVEY}

Random sample from each of the following clusters was used: students, post graduate students, and Internet café users because it concentrate on clusters of the population where the largest number of computer literate participants could be attained, which is a characteristic expected in both adopters and non-adopters questioned in this research (since the factors investigated in this research would not apply to computer-illiterate citizens and are outside the scope of this research).

This research used survey questionnaires to collect information on attitude towards e-government adoption from 897 participants randomly chosen from university students, postgraduate students and internet cafe users in Egypt The data was divided into two groups, those respondents who indicated that they had adopted e-government 335 (37\%), and those who had not 562 (63\%).

Based on the demographic analysis which helps to give a clearer picture of the characteristics of the data sate (sample chosen), it was found that the percentage of males who make use of egovernment in Egypt is more than females (53\%).This finding can be explained from cultural perspectives, the cultural and social values in the Arab countries, to which Egypt belongs, are based on gender segregation. Compared to males, females in Arab world are subject to a stricter set of rules, which limit their interaction and communications.

As for age it was found that the majority for e-government adopters were from 18-30 age categories which indicate that the young citizens in Egypt have higher motivation to adopt egovernment services than older citizens due to being more technology savvy at a younger age.The majority of the adopters are educated to college degree (78.8\%) which can indicate that highly educated citizens are more likely to have a higher level of education and occupation; hence, they may need an e-government system to conduct or complete any government service.

This study examined the different factors and their hypotheses indicated previously. Most of the survey items testing the hypotheses were adapted from previous studies [22]. The five-point Likert Scale was used to measure responses to the questions. Since English is not the first 
language of the respondents, who are not fluent in English, the questionnaire was translated into Arabic. For validation, reverse translation was used, with the questionnaire translated from English to Arabic first and then from Arabic to English.

\section{RESULTS}

Amos 21 and PASW 18 were used to test the goodness of fit of the model. The overall model fit was assessed using seven indices: Chi-square (X2), Degree of freedom/Chi-square (X2/df), Comparative Fit Index (CFI), Normed Fit Index (NFI), Goodness-of-Fit Index (GFI), Adjusted Goodness-of-Fit Index (AGFI) and (RMSEA)which is the Root Mean Square Error of Approximation.

The results as per Table 1 demonstrate that all indices had clearly exceeded the ideal standard values that were suggested for a good model fit, which means that the model had reached an acceptable level and could be used to explain the hypotheses. Hence, the path coefficients for each individual hypothesis of the structural model were tested next.

Table 1. Model Fit indices for the research model

\begin{tabular}{|l|l|l|l|}
\hline Fit Index & $\begin{array}{l}\text { Recommended } \\
\text { Value }\end{array}$ & Scores & Accepted fit? \\
\hline $\mathrm{X}^{2}$ & $\mathrm{p}>0.05$ & 0.839 & Yes \\
\hline $\mathrm{X}^{2} / \mathrm{df}$ & $<3.00$ & 1.386 & Yes \\
\hline GFI & $>0.90$ & 0.926 & Yes \\
\hline RMSEA & $<0.08$ & 0.000 & Yes \\
\hline RMSR & $<0.08$ & 0.061 & Yes \\
\hline AGFI & $>0.90$ & 0.935 & Yes \\
\hline NFI & $>0.90$ & 0.998 & Yes \\
\hline CFI & $>0.90$ & 1.000 & Yes \\
\hline
\end{tabular}

According to Table 2, path analysis of the research model showed Perceived Usefulness had a strong positive significant effect on Attitude $(\mathrm{H} 1, \beta=0.41, \mathrm{p}<0.001)$, but insignificant effect on BI $(\mathrm{H} 5, \beta=0.06, \mathrm{p}>0.05)$. Perceived Ease of Use had a moderate positive significant effect on Attitude $(\mathrm{H} 2, \beta=0.14, \mathrm{p}<0.01)$ and a strong positive significant effect on Perceived Usefulness (H4, $\beta=0.45, \mathrm{p}<0.001)$.

Behaviour Intention had strong positive significant effect on Electronic Government Actual Use (H6, $\beta=0.66, p<0.001)$. Trust in Government had a strong positive significant effect on Perceived Usefulness $(\mathrm{H} 13, \beta=0.13, \mathrm{p}<0.001)$ and a moderate positive effect on Perceived Ease Of Use (H14, $\beta=0.25, p<0.01$ ), while Trust in the Internet had weak positive effect on Perceived Usefulness $(\mathrm{H} 15, \beta=0.09, \mathrm{p}<0.05)$ and a strong positive effect on Perceived Ease Of Use (H16, $\beta=0.26, p<0.001)$. Website Design had moderate positive effect on both Perceived Usefulness $(H 17, \beta=0.189, p<0.01)$ and Perceived Ease of Use $(H 18, \beta=0.203, p<0.01)$. Public Value had significant strong positive effect on both Perceived Usefulness $(\mathrm{H} 19, \beta=0.166, p<0.001)$ and Perceived Ease of Use $(H 20, \beta=0.21, p<0.001)$.

With regard to how relationships between the different constructs explained the variances of their results (R2) (Table 3): Attitude explained 74\% of the variance in Behaviour Intention. Trust in Internet, Trust in Government, Public Values, and Website Design explained a range of 65-66\% of variance in Perceived Usefulness and Perceived Ease of Use. Perceived Ease of Use had the strongest effect on Perceived Usefulness compared to the other factors. Trust in Internet had the 
International Journal of Managing Information Technology (IJMIT) Vol.12, No.1, February 2020

strongest effect on Perceived Ease of Use compared to the other factors. Moreover, Perceived Ease of Use and Perceived Usefulness explained $60 \%$ of the variance in Attitude. Perceived Usefulness was found to be the strongest effect on Attitude. Lastly, Behaviour Intention explained $47 \%$ of variance in Electronic Government Actual Use. All associations can be seen to be strong to moderate between the constructs indicating the high value of goodness of fit of the model.

Table 2. Path analysis

\begin{tabular}{|l|l|l|l|l|}
\hline Hypothesis & $\begin{array}{l}\text { Path } \\
\text { (independent } \\
\text { dependent) }\end{array}$ & Path Coefficients $\beta$ & P-Value & Results \\
\hline H1 & PU $\rightarrow$ ATT & $0.41^{* * *}$ & 0.000 & Supported \\
\hline H2 & PEOU $\rightarrow$ ATT & $0.14^{* *}$ & 0.005 & Supported \\
\hline H3 & ATU $\rightarrow$ BI & $0.60^{* * *}$ & 0.000 & Supported \\
\hline H4 & PEOU $\rightarrow$ PU & $0.45^{* * *}$ & 0.000 & Supported \\
\hline H5 & PU $\rightarrow$ BI & 0.06 & 0.156 & Not supported \\
\hline H6 & BI $\rightarrow$ EGAU & $0.66^{* * *}$ & 0.000 & Supported \\
\hline H7 & EDU $\rightarrow$ PU & 0.64 & 0.096 & Not supported \\
\hline H8 & EDU $\rightarrow$ PEOU & 0.54 & 0.144 & Not supported \\
\hline H9a & TG $\rightarrow$ PU & $0.13^{* *}$ & 0.005 & Supported \\
\hline H9b & TG $\rightarrow$ PEOU & $0.25^{* *}$ & 0.005 & Supported \\
\hline H9c & TI $\rightarrow$ PU & $0.09^{*}$ & 0.021 & Supported \\
\hline H9d & TI $\rightarrow$ PEOU & $0.26^{* * *}$ & 0.000 & Supported \\
\hline H10 & WD $\rightarrow$ PU & $0.189^{* *}$ & 0.005 & Supported \\
\hline H11 & WD $\rightarrow$ PEOU & $0.203^{* *}$ & 0.003 & Supported \\
\hline H12 & PV $\rightarrow$ PU & $0.166^{* * *}$ & 0.000 & Supported \\
\hline H13 & PV $\rightarrow$ PEOU & $0.21^{* * *}$ & 0.000 & Supported \\
\hline$* * * \mathrm{P}<0.001, * * \mathrm{P}<0.01, ~ * P<0.05$ & & & \\
\hline
\end{tabular}

Table3. Coefficient of Determination $\left(\mathrm{R}^{2}\right)$

\begin{tabular}{|l|l|}
\hline Construct & $\mathbf{R}^{\mathbf{2}}$ \\
\hline SPU & 64.8 \\
\hline PEOU & 65.6 \\
\hline ATT & 60.4 \\
\hline BI & 74.9 \\
\hline EGAU & 47.0 \\
\hline
\end{tabular}

\section{DISCUSSION}

Perceived Ease of Use was confirmed as a variable affecting the adoption process through its multiple effects on key variables such as Perceived Usefulness and Attitude ( $\mathrm{H} 4, \mathrm{H} 2$ tested previously). As far as citizens perceive that the use of e-government services is free of effort (easy to use) their Attitude and Perceived Usefulness are increased. It is the responsibility of the government to elaborate e-services based on userse requirements and knowledge, in order to make them easy to use for the wide-range of citizens that exists in terms of Internet experience. This finding is also in line with earlier TAM research [8] and e-government adoption research [28], [29].

Perceived Usefulness is revealed as the most important factor affecting citizens ${ }^{\text {ee }}$ attitude (H1) (directly) to adopt e-government services. This gives evidence that, similar to other technology 
driven services, the perceived benefits derived from their use are the principal reason for citizens to adopt e-government services. The users form positive attitudes and strong intentions towards using the system, if the e-Government system is perceived to be useful. Managers in charge of the online provision of public services should take into account that potential users have to perceive the usefulness of the service in order to adopt it. These findings are consistent with previous TAM research that test and validate the consistent relationships between perceived usefulness, perceived ease of use and attitude [8], [30], [31], [32].

Attitude had a significant positive effect on Intention to use e-government services (H3). The findings demonstrated that citizense intention to use e-government service is most dominantly influenced by their attitude towards using these services and less so by perceived usefulness. However, prior research has suggested that the inclusion of attitude is not meaningful [8], [31] but this paper suggests otherwise, due to the voluntary nature of citizens" adoption of egovernment services. Voluntary users formed their intentions to use the systems mostly based on their attitude toward using the system. This result confirms the importance of Attitude in the TAM model, as this variable was removed from other versions of the TAM model.

Behavioural intention was found to have a significant positive effect on individualse actual use of e-government portals (H6). TAM originally hypothesises that, actual systems' use is directly determined by behavioural intention to re-use. These findings are consistent with [8], [28], [31]. Inconsistent with the proposition of the original TAM [8], this study found that PU did not directly affect citizens' intention to use e-government services (H5), but it directly affects their attitude, which means that Attitude construct fully mediates the effect of perceived usefulness on behavioural intention. The more useful the e-government website, the more the person feels good about the idea of using the e-government services, which will increase the intention to use this service.

In the present study, trust in e-Government comprised of two dimensions, namely trust in government (H9a, H9b) and trust in Internet technology (H9c, H9d). All these hypotheses were supported. High levels of Trust in government, and Trust in Internet would directly predict a higher level of users' belief in using e-government system, which means if the e-government services are not trustworthy, there is no reason why the citizens should anticipate getting any usefulness from using them. The government in Egypt lacks collaboration between its entities to draft laws and regulations related to ICT Usage, standardizing system use, and sharing information (according to interview results explained in the consequent chapter). These issues should be considered by the government in Egypt in order to increase citizens' trust and have them more willing to use government websites. These findings are consistent with [34].

Perceived Public Value (H12, H13) which is considered the consumer's overall assessment of the utility of a product based on the perceptions of what is received, and what is given, had a significant effect on users beliefs (Perceived usefulness, and Perceived Ease of Use). Higher level of Perceived Public Value, would predict a higher level of users' beliefs about using egovernment system. Government must concentrate on how to increase the value for the public from using e-government services in order to attract more people to use their online services; also e-government strategy must pay more attention to the requirements and expectations of users in developing e-government services. These findings are consistent with [35].

Website Design (H10, H11) was proved to be a significant predictor to the users' beliefs (Perceived Usefulness and Perceived Ease of Use. These findings are consistent with [36]. Citizens' adoption of e-government increases if e-government websites are available with adequate, attractive and well-organised design and content. Government agencies in Egypt should 
ensure that their websites are accessible to different users. The government in Egypt therefore should ensure that their websites are available with consistent and attractive screen layout. Also, the links on the websites should be updated as they should not lead to deleted or re-directed pages and to ensuring that people are comfortable in interacting with the government via the web-based channel.

\section{CONCLUSION}

This paper answered the following questions: What are the factors that influence the citizens' acceptance and adoption of e- government services in Egypt? And what is the relative importance of these factors and the relationship between them? By supporting predictions of the TAM model that Perceived Usefulness, Perceived Ease of Use, and Attitude positively influence the Behavioural intention regarding the use of e-government. Five external factors were included in the model: Trust in government, Trust in Internet, Website design, Perceived public value, and education level which four of them (Trust in government, Trust in Internet, Website design, and Perceived public value) were evidenced to be positively influential on e-government adoption.

Also the results of this study revealed that the research model explained $93 \%$ of the variance in citizens' intention to use e-government services according to the goodness of fit index. The hypothesised relationships between variables were moderately or significantly supported.

From a practical angle, this paper has contributed to better understanding e-government efforts particularly in an Egypt context by creating new adoption model, which is the extension of TAM model, to include social, political, and design influences; specifically, government and Internet trust, perceived public value, and website design dimensions and to identify the relationship between them.

The contribution of this model was that it demonstrated that Behavioural intention to use egovernment system was significantly affected by attitude, which in turns significantly influenced by users believes (perceived usefulness, and perceived ease of use). The external variables (government and Internet trust, perceived public value, and website design) significantly affect user's beliefs.

The empirical validation of the significant role of Attitude as a predictor of the citizen behavioural intention to use e-government services. Prior research had omitted this construct from TAM, usually in workplace settings, where the use of the technology most of the time is mandatory. The contribution of this study was providing evidence for the significant role of this construct in voluntary settings such as e-government adoption.

\section{LIMITATION AND FURTHER RESEARCH DIRECTIONS}

This study adopted cross-sectional design. This cross sectional study represents a slice of time, and does not show how the citizen's attitude and behaviour may change over time. Further study employing a longitudinal design would ascertain whether or not the citizen's attitude toward using e-government services has changed over time.

This research surveyed people who are Internet literate. This highlights the necessity to conduct a study with illiterate citizens. A qualitative method of data collection, such as interviews or focus groups, may be more suitable for people who struggle with the literacy required to complete written surveys. This would help to include all Egyptian citizens in the study of e-government adoption and increase the generalizability of the results. Furthermore, this may be helpful in 
International Journal of Managing Information Technology (IJMIT) Vol.12, No.1, February 2020

generating useful comparisons between the different perceptions of e-government adoption of internet-literate and - illiterate people.

The last limitation is derived from the geographical location of the current research. Although, the study findings are believed to be applicable to other Arab countries that share the same demographic characteristics with Egypt and provide their citizens with the same level of egovernment services, these findings are not necessarily applicable to other Arab countries that have lagged behind Egypt in terms of e-government. Therefore, further study in different countries would most likely strengthen and validate the findings on some of the hypotheses.

\section{REFERENCES}

[1] I. Lindgren, C. Madsen, S. Hofmann, and U. Melin, "Close encounters of the digital kind: A research agenda for the digitalization of public services". Government Information Quartely, 36(3), 427-436, 2019.

[2] A. Almukhlifi, H. Deng, and B. Kam, "E-Government Adoption in Saudi Arabia: The Moderation Effect of Wastta" (2018). CONF-IRM 2018 Proceedings. 9.

[3] G. Hu, J. Yan, W. Pan, S. R. Chohan and L. Liu, "The Influence of Public Engaging Intention on Value Co-Creation of E-Government Services," in IEEE Access, vol. 7, pp. 111145-111159, 2019.

[4] H. Naqvi, F. Chandio, A. Soomro and M. Abbasi, "Software as a Service Acceptance Model: A UserCentric Perspective in Cloud Computing Context," IEEE 5th International Conference on Engineering Technologies and Applied Sciences (ICETAS), Bangkok, Thailand, 2018, pp. 1-4.

[5] B. Distel, "Bringing Light into the Shadows: A Qualitative Interview Study on Citizens' NonAdoption of e-Government." Electronic Journal of e-Government. Vol. 16 Issue 2, p98-105, 2018.

[6] F. Sayed, "Innovation in public administration: the case of Egypt", United Nations Department for Economic and Social Affairs (UNDESA), 2004.

[7] V. Venkatesh, M. Morris, G. Davis, and F. Davis, "User acceptance of information technology: toward a unified view”, MIS Quarterly, vol.27, no.3, pp. 425, 2003.

[8] F. Davis, "Perceived usefulness, perceived ease of use, and user acceptance of information technology”, MIS Quarterly, vol.13, no.3, pp. 319, 1989.

[9] J. Fu, C. Farn, and W. Chao, "Acceptance of electronic tax filing: a study of taxpayer intentions", Information and Management, vol.43, no.1, pp. 109, 2006.

[10] I. Ajzen, "The theory of planned behaviour", Organizational Behaviour and Human Decision Processes, vol.50, no.2, pp. 179-211, 1991.

[11] L. Alzahrani, W. Al-Karaghouli and V. Weerakkody, "Investigating the impact of citizens' trust toward the successful adoption of e-government: A multi-group analysis of gender, age, and internet experience", Information Systems Management, 35:2, 124-146, 2018.

[12] H. McKnight, V. Choudhury, and C. Kacmar, "Developing and validating trust measures for ecommerce: an integrative typology", Information Systems Research, vol. 13, no. 3, pp. 334, 2002.

[13] I. Ajzen, "The Theory of Planned Behaviour", Organizational Behaviour and Human Decision Processes, vol.50, no.2, pp. 179-211, 1991.

[14] H. Deng, K. Karunasena, and W. Xu, "Evaluating the performance of e-government in developing countries: A public value perspective", Internet Research, Vol. 28 No. 1, pp. 169-190, 2018.

[15] M. Pura, "Linking perceived value and loyalty in location based mobile services," Managing service quality, vol.15, no.6, pp. 509, 2005. 
International Journal of Managing Information Technology (IJMIT) Vol.12, No.1, February 2020

[16] S. Becker, “A e-government visual accessibility for older adult users", Social Science Computer Review, vol. 22 no. 1, p. 11, 2004.

[17] C. Bertot, and P. Jaeger, "User-centred e-government: challenges and benefits for government web sites”, Government Information Quarterly, vol. 23 no. 2, pp. 163, 2006.

[18] P. Zhang, and G. von Dran, "Satisfiers and dissatisfiers: a two-factor model for website design and evaluation", Journal of the American Society for Information Science, vol. 51, no. 14, pp. 1253, 2000.

[19] E. Rogers, "Diffusion of Innovation”,3rdEd, FreePress, New York, 1995.

[20] National Telecommunications and Information Administration (NTIA). "A nation online: how Americans are expanding their use of the internet". Washington D.C: US Department of Commerce, 2002

[21] M. Johar and J.Awalluddin. "The Role of Technology Acceptance Model in Explaining Effect on ECommerce Application System”. International Journal of Managing Information Technology, vol.3, $1-14,2011$

[22] H. Yang, and Y. Yoo, "It's all about attitude: revising the technology acceptance model", Decision Support Systems, vol.38, no.1, pp. 19, 2004

[23] M. Fassnacht, and L. Koese, "Quality of electronic services conceptualizing and testing a hierarchical model", Journal of service research, vol.9, no.1, pp.19, 2006

[24] R. Campeau and A. Higgins, "Application of social cognitive theory to training for computer skills", Information system Research, pp. 118, 1995.

[25] L. Shore, V. Power, A. De Eyto, and W. O’Sullivan, “Technology Acceptance and User-Centred Design of Assistive Exoskeletons for Older Adults: A Commentary". Robotics 2018, 7, 3 ..

[26] C. Or, and B. Karsh, "A systematic review of patient acceptance of consumer health information technology", Journal of the American Medical Informatics Association, vol.16, no. 4 pp. 550-560, 2009.

[27] M. Thaker,A. Pitchay, H. Thaker, and M. Amin, "Factors influencing consumers' adoption of Islamic mobile banking services in Malaysia: An approach of partial least squares (PLS)", Journal of Islamic Marketing, Vol. 10 No. 4, pp. 1037-1056, 2019.

[28] T.Danh, "Trust, Perceived Useful, Attitude and Continuance Intention to Use E-Government Service: An Empirical Study in Taiwan",IEICE TRANSACTIONS on Information and Systems, Vol.E102D, no. 12, pp. 2524-2534, 2019.

[29] A.Hamid, F.Abdul Razak, A.Abu Bakar, W.Abdullah, "The Effects of Perceived Usefulness and Perceived Ease of Use on Continuance Intention to Use E-Government", Procedia Economics and Finance, Vol.35, pp. 644-649, 2016.

[30] I. Chang, Y. Li, F. Hung, and G. Hwang, "An empirical study on the impact of quality antecedents on tax payers acceptance of internet tax-filing systems", Government Information Quarterly, Vol. 22 No. 3, pp. 389-410, 2005.

[31] V.Venkatesh, F.Davis, "A Theoretical Extension of the Technology Adoption Model: Four Longitudinal Field Studies”, Management Science, vol.46, no.2, pp. 186, 2000.

[32] Z. Yang, M. Jun. and T. Peterson, "Measuring customer perceived online service quality: scale development and managerial implication", International Journal of operations and production management, vol.24, no.11, pp.1149, 2004.

[33] M. Qasem, A. Zolait, "Determinants of Behavioural Intentions towards Using E-Government Services in the Kingdom of Bahrain”, International Journal of Computing and Digital Systems, Vol. 5, 2016. 
International Journal of Managing Information Technology (IJMIT) Vol.12, No.1, February 2020

[34] L. Alzahrani, W. Al-Karaghouli, V. Weerakkody, "Analysing the critical factors influencing trust in e-government adoption from citizens' perspective: A systematic review and a conceptual framework", International Business Review, Vol. 26, No. 1, pp. 164-175, 2017

[35] Y. Li, H. Shang, "Service quality, perceived value, and citizens' continuous-use intention regarding egovernment: Empirical evidence from China," Information \& Management, 2019.

[36] B. Berlilana, T. Hariguna, T. Lai, "Effects of Relationship Quality on Citizen Intention Use of Egovernment Services: An Empirical Study of E-government System," International Journal of Electrical and Computer Engineering; Yogyakarta Vol. 8, No. 6, pp. 5127-5133, 2018.

\section{AuTHORS}

Sara EIKheshin, PHD She is an Assistant professor in Arab Academy for Science, Technology and Maritime Transport, Alexandria, Egypt. She has 20 years working experience in Business Information System department, her research interest is e-government and database

Noha Saleeb, PHD, MSC, BArch, FHEA She is an Associate Professor in Creative Technologies in Design Engineering \& Maths department at Science \& Technology School in Middlesex University, London, UK 